\title{
Определение условий модификации анионитов AН-31 и АРА-8п иммобилизацией 5-(4-карбоксифенил-азо)-роданина
}

\author{
Увайсова С.М. ${ }^{1,2}$, Бабуев М.А. ${ }^{1}$ \\ ${ }^{1}$ ФГБОУ ВО «Дагестанский государственный университет», Махачкала \\ ${ }^{2}$ Дагестанский научный иентр Российской академии наук, Махачкала
}

Поступила в редакцию 15.04.2019 г.

DOI: https://doi.org/10.17308/sorpchrom.2019.19/751

Исследованы условия сорбции органического аналитического реагента - 5-(4-карбоксифенилазо)-роданина из водных растворов высокоосновным анионитом АРА-8п $\left(\mathrm{Cl}^{-}\right.$- форма) и слабоосновным анионитом AН-31 (ОН - форма) в статическом режиме. Определены сорбционные емкости анионитов по реагенту. По форме начальных участков изотермы сорбции определено, что сорбция относится к классу Н и механизм хемосорбционный. Изучена десорбция реагента растворами $\mathrm{HCl}, \mathrm{NaCl}$, $\mathrm{NaOH}$ различных концентраций. Показано, что более устойчивым является модифицированный сорбент, полученный на основе анионита АРА-8п.

Ключевые слова: сорбция, аниониты АН-31 и АРА-8п, 5-(4-карбоксифенил-азо)-роданин, модифицированный хелатный сорбент, десорбция.

\section{Determination of the conditions for the modification of AN-31 and ARA-8p anion exchangers by immobilization of 5-(4-carboxyphenyl-azo)-rodanine}

\author{
Uvaysova S.M. ${ }^{1,2}$, Babuev M.A. ${ }^{1}$ \\ IFSBEI HPE «Dagestan State University», Makhachkala \\ 2Dagestan Scientific Center of the Russian Academy of Sciences, Makhachkala
}

The paper is devoted to the determination of optimal conditions for the modification of the ARA-8P and AN-31 anion exchangers with an analytical organic reagent - 5-(4-carboxyphenyl-azo)-rodanine in order to obtain new chelating sorbents.

Studies were conducted in a static mode at different $\mathrm{pH}$ values, time and concentrations of the reagent. Quantitative changes in the "water phase - anion exchanger" system were estimated by the optical densities of aqueous solutions, which were measured by spectrophotometric analysis (at $420 \mathrm{~nm}$ ) on a LEKI SS 1207 spectrophotometer.

The optimal conditions for the sorption of 5-(4-carboxyphenyl-azo)-rodanine on the highly basic anion exchanger APA-8P and the weakly basic anion exchanger AN-31 have been established. The sorption of the modifier by anion exchangers in the $\mathrm{pH}$ range from 1.0 to 12.0 was investigated. It is determined that the optimal sorption of the reagent is observed at $\mathrm{pH}$ 5.0-9.0. Given that the solubility of the reagent is higher in an alkaline medium, subsequent experiments were carried out at $\mathrm{pH} 9.0$. The dependence of the modifier sorption on the phase contact time was studied. The maximum degree of sorption of - 5-(4-carboxyphenylazo)-rodanine on ARA-8P is observed after 10 minutes of contact of the sorbent with the sorbate, and on AN31 - after 30 minutes. The sorption capacities of AN-31 and ARA-8P were determined by reagent, which were $0.5 \mathrm{mmol} / \mathrm{g}$ and $1.18 \mathrm{mmol} / \mathrm{g}$, respectively. The shape of the initial sections of the sorption isotherm is related to class $\mathrm{H}$, indicating extremely strong adsorption at very low concentrations and the formation of 
chemical bonds. This fact also indicates that the interaction between the adsorbed structural particles is negligible and the activation energy does not depend on the degree of surface filling. The stability of modified sorbents in solutions of $\mathrm{HCl}, \mathrm{NaCl}, \mathrm{NaOH}$ of various concentrations was investigated. From the data obtained, it can be concluded that the sorbent obtained on the basis of ARA-8P anion-exchanger is more stable.

These results can be used for extracting organic reagent from aqueous solutions, and the resulting polymer sorbents for the extraction of toxic metal ions from natural and waste waters.

Keywords: sorption, anion exchangers' AN-31 and ARA-8p, 5-(4-carboxyphenyl-azo)-rodanine, modified chelate sorbent, desorption.

Введение

Полимерные хелатообразующие сорбенты обеспечивают избирательное извлечение тяжелых металлов из сложного состава. Преимуществом модифицированных сорбентов, которые получают сорбцией органических реагентов обычными ионообменниками является простота их получения $[1,2]$. При выборе носителя необходимо учитывать наличие функционально-аналитических групп, которые обеспечивают селективное извлечение тяжелых металлов.

Азосоединения на основе роданина и ароматических аминов, содержащих солеобразующие группы $\left(-\mathrm{OH},-\mathrm{SO}_{3} \mathrm{H},-\mathrm{COOH},-\mathrm{AsO}_{3} \mathrm{H}_{2}\right)$ представляют интерес для определения тяжелых металлов [3]. Они взаимодействуют с ионами металлов в растворах с образованием устойчивых, хорошо растворимых окрашенных соединений, характеризирующиеся высокой чувствительностью (молярный

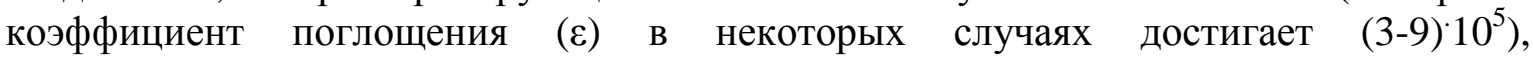
контрастностью и избирательностью по отношению к металлам.

Создание новых комплексообразующих сорбентов и использование их для концентрирования и разделения элементов является одним из перспективных направлений аналитической химии.

Целью данной работы является изучение условий модифицирования анионитов АРА-8п и АН-31 аналитическим органическим реагентом 5-(4карбоксифенил-азо)-роданин.

\section{Эксперимент}

В качестве основы для модификации были выбраны высокоосновной анионит APA-8п (Cl-форма) и слабоосновный анионит АН-31 ( $\mathrm{OH}^{-}$-форма). В качестве модификатора использовали 5-(4-карбоксифенил-азо)-роданин, синтезированный и очищенный по методике [4]. Условия модифицирования анионитов изучали спектрофотометрическим методом анализа. Подготовку анионитов проводили по методике, приведенной в работе [5]. Растворы реагента готовили растворением точной навески в $0.01 \mathrm{M}$ растворе гидроксида натрия.

Для создания в исследуемых системах определенного значения $\mathrm{pH}$ использовали $0.1 \mathrm{M}$ растворы $\mathrm{HCl}$ и $\mathrm{NaOH}$. Значения $\mathrm{pH}$ исследуемых растворов контролировали универсальным иономером рН-150МИ. Массу веществ измеряли на аналитических весах HTR-220CE. Контакт фаз осуществляли на перемешивающем устройстве LS 220. Оптическую плотность растворов измеряли на спектрофотометре LEKI SS 1207.

Для установления величины кислотности среды модифицирования сорбентов готовили серию растворов реагента в мерных колбах на $25 \mathrm{~cm}^{3}$ с концентрацией $1.0 \cdot 10^{-4} \mathrm{M}$ и устанавливали значения $\mathrm{pH}$ от 1.0 до 12.0. Содержимое колб переносили в бюксы на $100 \mathrm{~cm}^{3}$, куда предварительно вносили по 0.1 г анионита, и окончательное значение $\mathrm{pH}$ подтверждали в присутствии анионита. Бюксы ставили на перемешивание при температуре $20 \pm 2^{\circ} \mathrm{C}$. По истечении 30 минут сорбент отделяли фильтрованием беззольными фильтрами марки «синяя лента». Сорбент на фильтре промывали $1.0 \cdot 10^{-3} \mathrm{M}$ раствором $\mathrm{NaOH}$. Промывные воды и фильтрат переносили в мер- 
ную колбу на $50 \mathrm{~cm}^{3}$, в которой создавали необходимые значения $\mathrm{pH}$, доводили до метки дистиллированной водой и измеряли оптическую плотность в пределах видимой области спектра $(\lambda=380-700$ нм).

Степень сорбции $(\mathrm{R}, \%)$ рассчитывали по формуле

$$
R, \%=\frac{C_{u c x}-C_{\text {paвн }}}{C_{u c x}} \cdot 100,
$$

где $\mathrm{C}_{\text {исх }}$ - исходная концентрация реагента, $\mathrm{M}$; $\mathrm{C}_{\text {равн }}-$ концентрация реагента после сорбции, М.

По полученным данным строили графики зависимости $\mathrm{R}, \%=\mathrm{f}(\mathrm{pH})$ и по ним определяли область значений $\mathrm{pH}$, при котором наблюдается максимальное значение степени извлечения реагента анионитом.

Экспериментально изучена зависимость степени сорбции 5-(4карбоксифенил-азо)-роданина на анионитах АН-31 и АРА-8п от продолжительности контакта фаз. На механическом встряхивателе перемешивали растворы реагента с концентрацией $1.0 \cdot 10^{-4} \mathrm{M}$ и 0.1 г анионита в интервале времени от 10 до 120 минут $(10 ; 20 ; 30 ; 60 ; 120)$ при рН=9.0. Дальнейшую обработку проводили по вышеуказанной схеме. Доводили $\mathrm{pH}$ до 9.0 и измеряли оптическую плотность фильтрата при длине волны максимального светопоглощения реагента в кювете с толщиной $1 \mathrm{~cm}$ относительно нулевого раствора.

Равновесные концентрации рассчитывали по предварительно построенной градуировочной зависимости в координатах $\mathrm{A}=\mathrm{f}\left(\mathrm{C}_{\mathrm{R}}\right)$. По результатам эксперимента строили графики зависимости $\mathrm{R}, \%=\mathrm{f}(\mathrm{tмин})$, по которым определяли значение времени контакта фаз, при котором сорбция реагента максимальна.

Для определения сорбционной емкости готовили серию растворов с одинаковой массой анионитов и возрастающей концентрацией реагента от $1.0 \cdot 10^{-4} \mathrm{M}$ до $8.010^{-3} \mathrm{M}$, устанавливали $\mathrm{pH} 9.0$ и перемешивали в течение 10 минут и 30 минут, для AРА-8п и АН-31 соответственно. Дальнейшую обработку проводили по вышеуказанной схеме. Доводили рН до 9.0 и измеряли оптическую плотность.

Величину сорбции (а, ммоль/г) находили по формуле:

$$
a=\frac{\left(C_{u c x}-C_{\text {равн }}\right) \cdot V}{m_{c}},
$$

где $\mathrm{C}_{\text {исх }}$ - исходная концентрация реагента, $\mathrm{M} ; \mathrm{C}_{\text {равн }}$ - концентрация реагента после сорбции, M; V - объем раствора, см $^{3} ; \mathrm{m}_{\mathrm{c}}$ - масса сорбента, г.

Для изучения устойчивости высушенных полученных модифицированных сорбентов в различных реакционных средах навески их по 0.1 помещали в конические колбы, заливали испытуемым раствором (элюентом) и перемешивали на механическом встряхивателе в течение 30 минут. Затем декантировали раствор реагента в кюветы с толщиной 1 см и измеряли значения оптической плотности. Концентрации десорбированного реагента определяли по градуировочной зависимости.

Исходя из известной величины сорбции $(a)$, объема элюента $(\mathrm{V})$, навески модифицированного сорбента $\left(\mathrm{m}_{\mathrm{c}}\right)$ и концентрации десорбированного реагента $\left(c_{\text {равн }}\right)$, рассчитывали степень его десорбции $(d)$ по формуле (3)

$$
d, \%=\frac{V \cdot C_{\text {равн }}}{a \cdot m_{c}} \cdot 100 .
$$

\section{Обсуждение результатов}

Для установления структуры реагента снят его ИК-спектр, приведенный на рис. 1. Также сняты ИК-спектры исходных анионитов и модифицированных сорбен- 
тов (рис. 2-3). Спектры снимали на ИК-Фурье спектрометре «Vertex 70» («Bruker» Германия) АЦКП ДНЦ РАН по стандартной методике для порошковых образцов путем перемешивания с бромидом калия в пропорции 1:300 и дальнейшим прессованием в таблетку с толщиной 2 мм.

Как следует из рис. 1 обнаружена новая полоса поглощения в области $1420 \mathrm{~cm}^{-1}$, соответствующая поглощению $-\mathrm{N}=\mathrm{N}$ - группе, что свидетельствует об образовании нового реагента. Следует отметить, что данная группа отсутствует в структуре исходных веществ.

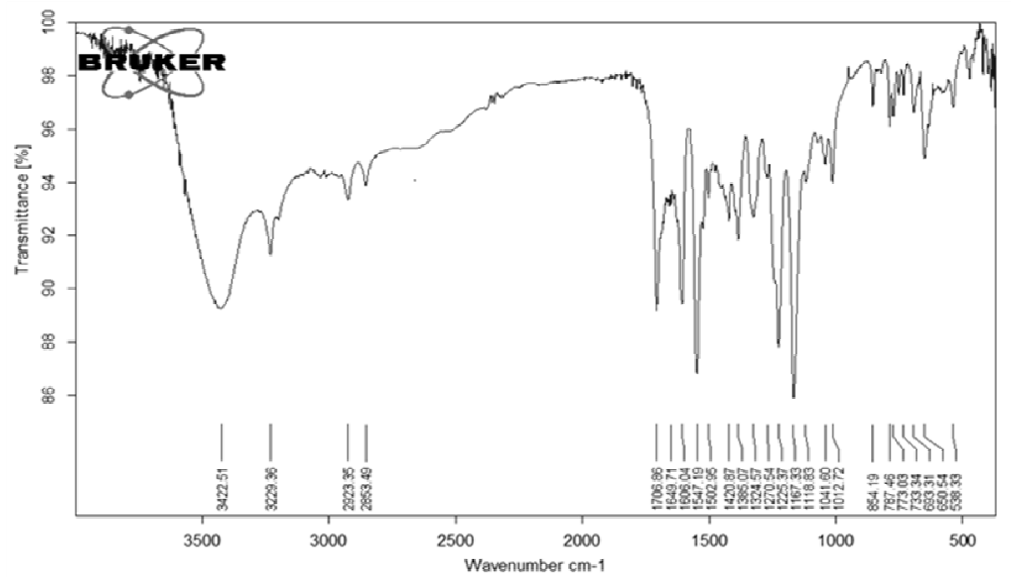

Рис. 1. ИК-спектр 5-(4-карбоксифенил-азо)-роданина

Как видно из рис. 2, на ИК-спектре модифицированного сорбента на основе АН-31 интенсивность полос в области 1637, 1459, 1036 и 617 см$^{-1}$ уменьшается по сравнению со спектром анионита АН-31. Обнаружены полосы поглощения для групп, идентичные полосам поглощения спектра 5-(4-карбоксифенил-азо)-роданина, 3435, 2925, 1637, 1556, 1231 и 865 см$^{-1}$. Изменение интенсивности полосы поглощения в области $1637 \mathrm{~cm}^{-1}$, соответствующая поглощению карбоксильной группы, свидетельствует об образовании нового сорбента через образование ионной связи по следующей схеме:

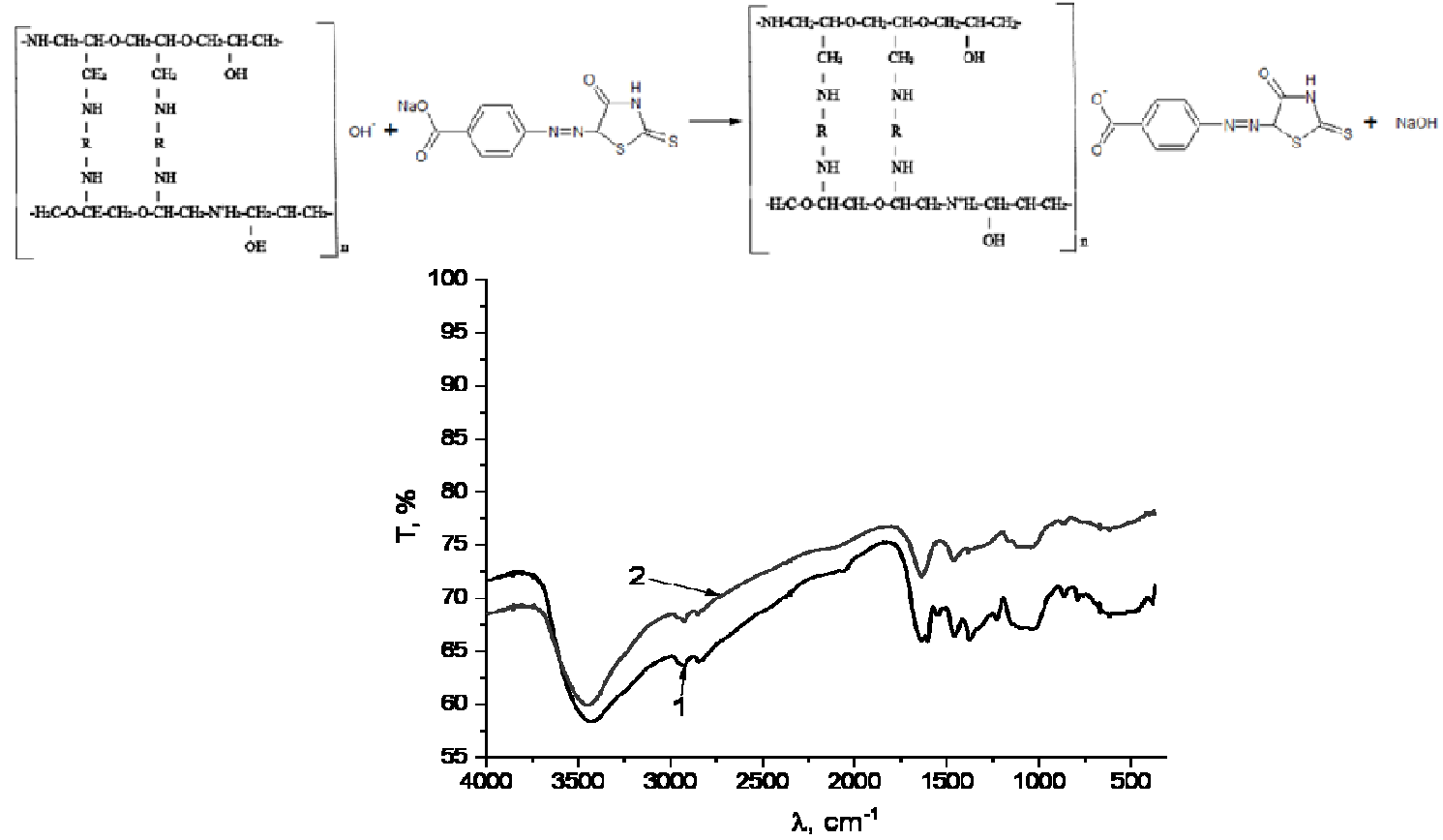

Рис. 2. ИК-спектры модифицированного сорбента на основе анионита АН-31 5-(4-карбоксифенил-азо)-роданином (1) и анионита АН-31 (2) 
Как видно из рис. 3, на ИК-спектре модифицированного сорбента на основе AРА-8п меняется интенсивность полос в области 1474, 1372, 1220, 1137, 1097 и $991 \mathrm{~cm}^{-1}$ по сравнению со спектром анионита AРА-8п. Обнаружены полосы поглощения для групп, идентичные полосам поглощения спектра 5-(4карбоксифенил-азо)-роданина, 3445, 2921, 1603, 1372, 1220 и $702 \mathrm{~cm}^{-1}$. Изменение интенсивности полосы поглощения в области $1603 \mathrm{~cm}^{-1}$, соответствующая поглощению карбоксильной группы, свидетельствует об образовании нового сорбента через образование ионной связи по следующей схеме:
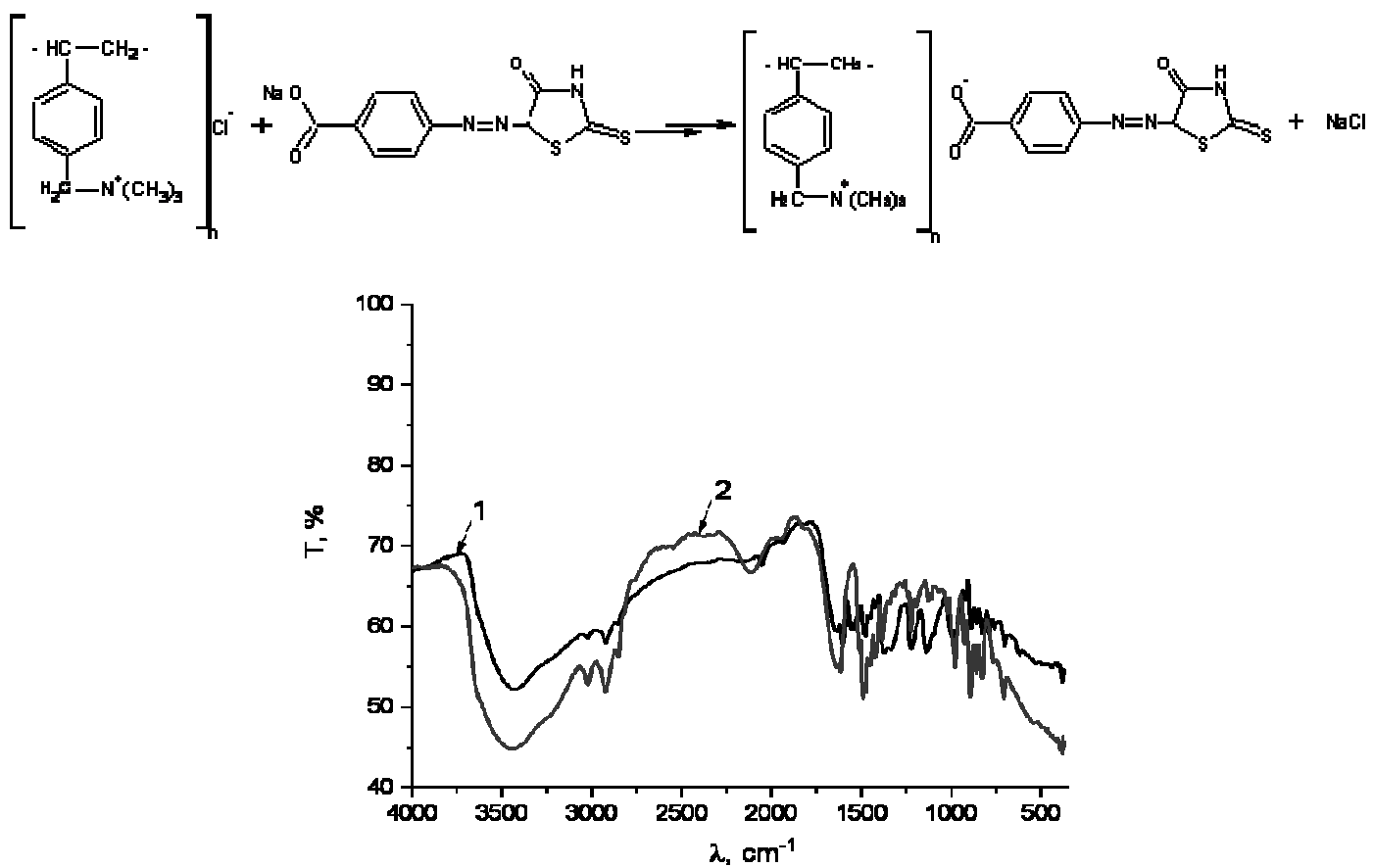

Рис. 3. ИК-спектры модифицированного сорбента на основе анионита АРА-8п 5-(4-карбоксифенил-азо)-роданином (1) и анионита АРА-8п (2)

Структура реагента подтверждена исследованием его поверхности сканирующим электронным микроскопом - ASPEX Express на базе EDX детектора OmegaMax (рис. 4), по которой можем судить об игольчатой структуре кристаллов в соответствии с методикой синтеза [4].

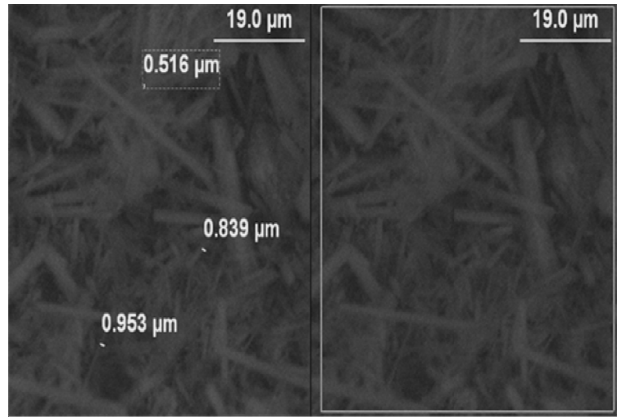

Рис. 4. EDX-спектр 5-(4карбоксифенил-азо)-роданина

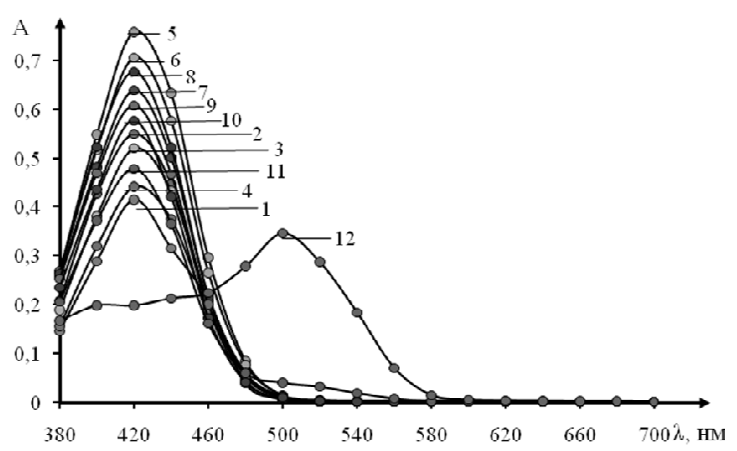

Рис. 5. Зависимость светопоглощения 5-(4-карбоксифенил-азо)-роданина от $\mathrm{pH}$ раствора $\left(\mathrm{C}_{\mathrm{R}}=2 \cdot 10^{-5} \mathrm{M}\right)(1-\mathrm{pH} 1,2-\mathrm{pH} 2,3-$ $\mathrm{pH} \mathrm{3,} \mathrm{4-pH} \mathrm{4,} \mathrm{5-pH} \mathrm{5,} \mathrm{6-pH} \mathrm{6,} \mathrm{7-pH} \mathrm{7,} \mathrm{8-pH}$ 8, 9-pH 9, 10-pH 10, 11-pH 11, 12-pH 12) 
Для установления длины волны, при котором наблюдается максимальное поглощение, сняты спектры синтезированного реагента при различных значениях $\mathrm{pH}$ (рис. 5). Как следует из рис. 5, в интервале $\mathrm{pH}$ 1.0-11.0 максимальная оптическая плотность наблюдается при длине волны $\lambda=420$ нм. При рН 12 и больше максимум смещается батохромно. Результаты изучения влияния $\mathrm{pH}$ раствора на степень сорбции представлены на рис. 6:

Как видно из рис. 6, максимальная сорбция реагента наблюдается при рН 5.09.0. Учитывая, что растворимость реагента выше в щелочной среде, последующие эксперименты проводили при $\mathrm{pH}=9.0$.

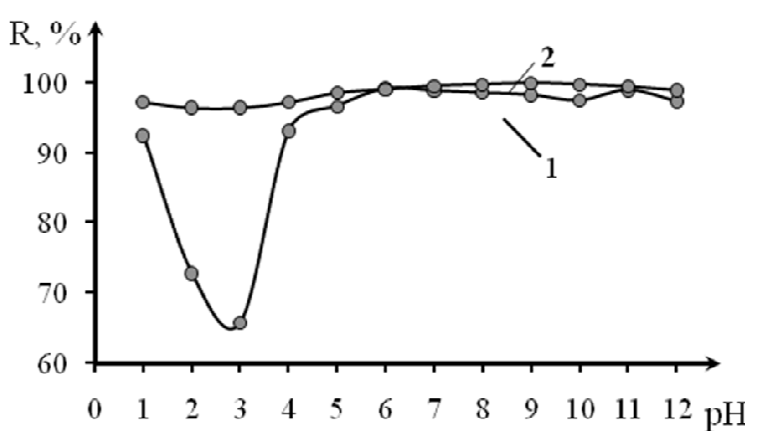

Рис. 6. Зависимость степени сорбции

$\mathrm{R}(\%)$ 5-(4-карбоксифенил-азо)-

роданина от $\mathrm{pH}$ на АН-31 (1) и АРА-8п

(2) $\left(\mathrm{m}_{\mathrm{a}}=0.1 \Gamma, \mathrm{C}_{\mathrm{R}}=1.0 \cdot 10^{-4} \mathrm{M}\right)$

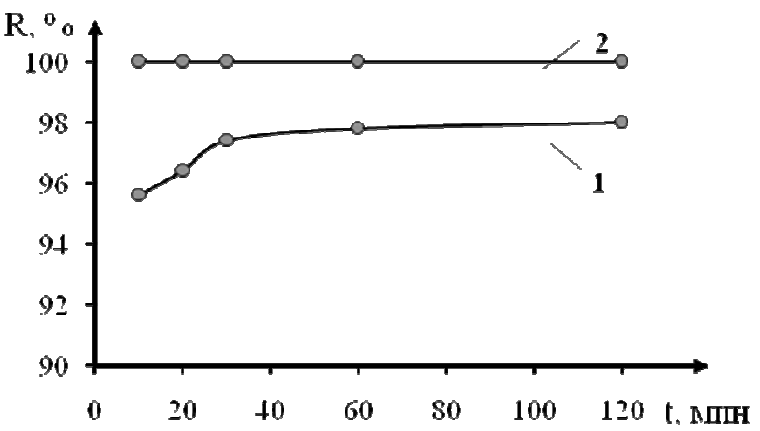

Рис. 7. Зависимость степени сорбции $\mathrm{R}(\%)$ от времени контакта фаз 5-(4карбоксифенил-азо)-роданина с АН-31

(1) и АРА-8п (2) $\left(\mathrm{m}_{\mathrm{a}}=0.1\right.$ г, $\left.\mathrm{C}_{\mathrm{R}}=1.0 \cdot 10^{-4} \mathrm{M}\right)$

Графические зависимости степени сорбции модификатора от времени контакта фаз представлены на рис. 7. Сорбционное равновесие достигается при перемешивании в течение 10 минут для АРА-8п и 30 минут АН-31, что свидетельствует о достаточно быстром достижении равновесия в изучаемых системах.

Данные по анализу кривых насыщения (рис. 8) дают основание предполагать, что в точке насыщения их проекции на ось ординат указывают на величину сорбционной емкости анионитов по отношению к сорбируемому реагенту СЕС (ммоль/г).

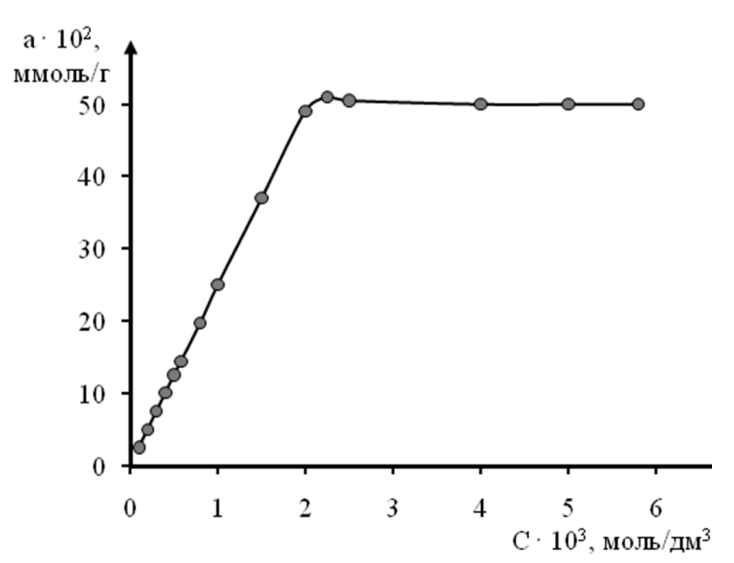

a

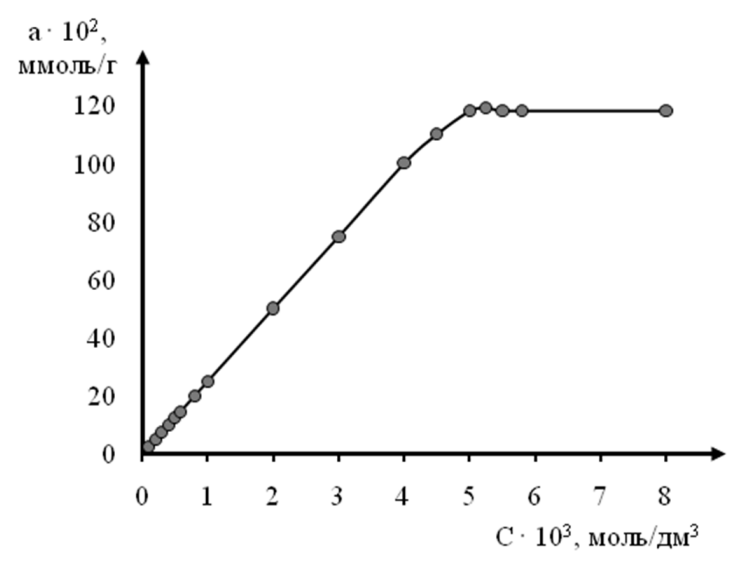

6

Рис. 8. Кривые насыщения АН-31 (а) и АРА-8п (б)

5-(4-карбоксифенил-азо)-роданином $\left(\mathrm{m}_{\mathrm{a}}=0.1\right.$ г)

Статическая емкость АН-31 и АРА-8п по сорбируемому реагенту, определенная по рис. 8, составила 0.5 ммоль/г и 1.18 ммоль/г соответственно. Исходя из форм начальных участков изотерм сорбции реагента анионитом АН-31 (рис. 9) и анионитом АРА-8п (рис. 10) можно сделать вывод о том, что полученные изотермы отно- 
сятся к классу Н по классификации Гильса. Изотермы класса Н наблюдаются при чрезвычайно сильной адсорбции при очень низких концентрациях и в тех случаях, когда сопровождается образованием химических соединений (хемосорбция). Этот факт также свидетельствует о том, что взаимодействие между адсорбированными структурными частицами пренебрежимо мало и энергия активации не зависит от степени заполнения поверхности.

Из-за чрезвычайно высокой сорбции исследуемого реагента, для описания данных изотерм невозможно применение моделей изотерм Лэнгмюра, Темкина и Фрейндлиха.

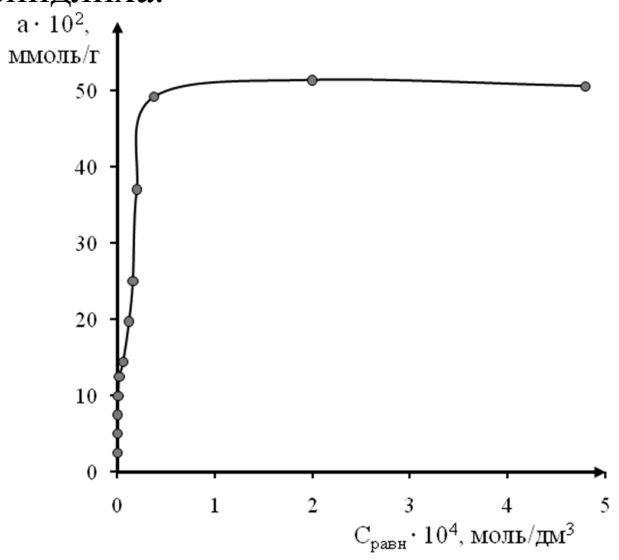

Рис. 9. Изотерма сорбции 5-(4-карбоксифенил-азо)-роданина AH-31 $\left(\mathrm{m}_{\mathrm{a}}=0.1 \Gamma\right)$

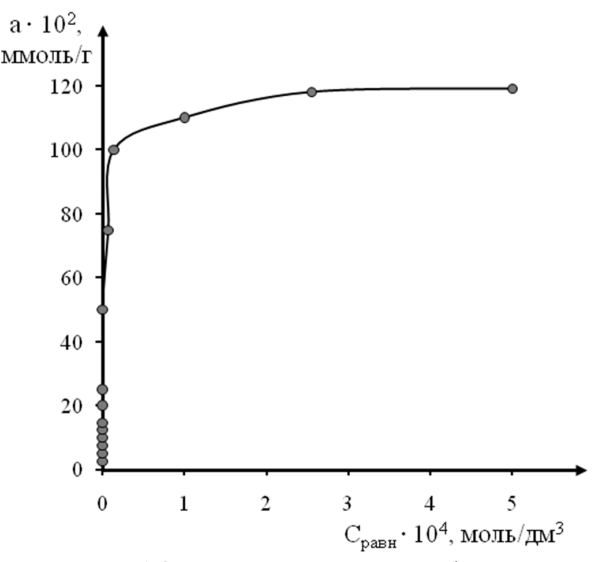

Рис. 10. Изотерма сорбции 5-(4-карбоксифенил-азо)-роданина АРА-8ח $\left(\mathrm{m}_{\mathrm{a}}=0.1\right.$ г)

В качестве элюентов выбраны растворы $\mathrm{HCl}, \mathrm{NaCl}, \mathrm{NaOH}$ различных концентраций, так как они могут быть потенциальными десорбентами для тяжелых металлов с модифицированных сорбентов. Значения степени десорбции модификатора в зависимости от концентрации элюента представлены в табл. 1.

Таблица 1. Зависимость степени десорбции 5-(4-карбоксифенил-азо)-роданина от концентрации элюента

\begin{tabular}{|c|c|c|c|}
\hline \multirow{3}{*}{ Элюент } & \multirow{2}{*}{ Концентрация элюента, } & \multicolumn{2}{|c|}{ Степень десорбции d, \% } \\
\cline { 2 - 4 } & & $\mathrm{AH}-31$ & $\mathrm{APA}-8$ п \\
\hline \multirow{3}{*}{$\mathrm{HCl}$} & 0.5 & 2.7 & 0.4 \\
\cline { 2 - 4 } & 1.0 & 3.0 & 0.5 \\
\cline { 2 - 4 } & 2.0 & 3.5 & 0.7 \\
\cline { 2 - 4 } & 3.0 & 4.8 & 0.9 \\
\hline \multirow{3}{*}{$\mathrm{NaCl}$} & 4.0 & 5.1 & 0.0 \\
\cline { 2 - 4 } & 0.5 & 0.5 & 0.16 \\
\cline { 2 - 4 } & 1.0 & 1.4 & 0.23 \\
\cline { 2 - 4 } & 2.0 & 3.7 & 0.30 \\
\hline \multirow{3}{*}{$\mathrm{NaOH}$} & 3.0 & 5.5 & 0.35 \\
\cline { 2 - 4 } & 4.0 & 6.2 & 0.1 \\
\cline { 2 - 4 } & 0.5 & 3.6 & 0.1 \\
\cline { 2 - 4 } & 1.0 & 69.5 & 0.2 \\
\cline { 2 - 4 } & 2.0 & 100.0 & 0.4 \\
\hline
\end{tabular}


Как показывают полученные результаты, наиболее стабильным является сорбент на основе анионита АРА-8п. С сорбента на основе анионита АН-31 растворы $\mathrm{HCl}$ и $\mathrm{NaCl}$ существенно не десорбируют. Растворы $\mathrm{NaOH}$ с концентрацией $1 \mathrm{M}$ значительно десорбируют реагент с анионита АН-31, а при концентрации 2 М и более наблюдается полная десорбция.

\section{Заключение}

Определены условия сорбции 5-(4-карбоксифенил-азо)-роданина на высокоосновном анионите АРА-8п и слабоосновном анионите АН-31. Исследована сорбция модификатора анионитами в диапазоне $\mathrm{pH}$ от 1.0 до 12.0. Установлено, что максимальная сорбция реагента наблюдается при рН 5.0-9.0. Максимальная степень сорбции 5-(4-карбоксифенил-азо)-роданина на АРА-8п наблюдается после 10 мин контакта сорбента с сорбатом, а на АН-31 - после 30 мин. Определены сорбционные емкости АН-31 и АРА-8п по реагенту, которые составили 0.5 ммоль/г и 1.18 ммоль/г соответственно. По форме начальных участков изотермы сорбции соотнесены к классу Н, свидетельствующей о чрезвычайно сильной адсорбции при очень низких концентрациях и об образовании химических связей. Исследована устойчивость модифицированных сорбентов в растворах $\mathrm{HCl}, \mathrm{NaCl}, \mathrm{NaOH}$ различных концентраций. Установлено, что более стабильным является сорбент, полученный на основе анионита АРА-8п.

\section{Список литературы}

1. Штокало М.И., Костенко Е.Е., Жук. И.З. // Журнал аналитической химии. 1991. Т. 46. № 6. C. 1093-1097.

2. Золотов Ю.А. Сорбционное концентрирование микрокомпонентов из растворов. Применение в неорганическом анализе. М. Наука. 2007. 330 с.

\section{References}

1. Shtokalo M.I., Kostenko E.E., Zhuk. I.Z., Zhurnal analiticheskoi khimii, 1991, Vol. 46, No 6, pp. 1093-1097.

2. Zolotov Ju.A. Sorbcionnoe koncentrirovanie mikrokomponentov iz rastvorov. Primenenie $\mathrm{v}$ neorganicheskom analize, M.,Nauka Publ., 2007, 317 p.
3. Прописцова Р.Ф., Саввин С.Б. // Журнал аналитической химии. 1973. Т. 28. № 2. С. 2277-2283.

4. Грищук А.П., Баранов С.Н. // Журнал аналитической химии. 1958. Т. 28. № 4. С. 896-900.

5. Бюрниева У.Г. Дисс. канд. хим. наук. Краснодар. 2009. 110 с.

3. Propiscova R.F., Savvin S.B., Zhurnal analiticheskoi khimii, 1973, Vol. 28, No 2, pp. 2277-2283.

4. Grishchuk A.P., Baranov S.N., Zhurnal analiticheskoi khimii, 1958, Vol. 28, No 4, pp. 896-900.

5. Bjurnieva U.G. Diss. kand. chem. nauk. Krasnodar, 2009, 110 p.

Увайсова Саида Магомедзагировна - аспирант кафедры аналитической и фармацевтической химии, Дагестанский государственный университет, Дагестан, Махачкала, тел.: +7 (903) 428-31-83

Бабуев Магомед Абдурахманович - доцент кафедры аналитической и фармацевтической химии, д.х.н., Дагестанский государственный университет, Дагестан, Махачкала, тел.: +7 (963) 792-18-40
Uvaysova Saida M. - the postgraduate student, department of analytical and pharmaceutical chemistry, Dagestan State University, Dagestan Pepublic, Makhachcala, E -mail: smuvaisova@mail.ru

Babuev Magomed A. - Ph.D. (chemistry), associate prof department of analytical and pharmaceutical chemistry Dagestan State University, Dagestan Pepublic, Makhachcala, e-mail: babuev77@ mail.ru 